\title{
Feasibility of Utilizing Ethnic Beauty Salons for Cervical Cancer Screening Education
}

Western Journal of Nursing Research $|-2|$

(C) The Author(s) 2014 Reprints and permissions: sagepub.com/journalsPermissions.nav DOI: $10.1177 / 0193945914529025$

wjn.sagepub.com

@SAGE

\section{Jongwon Lee', Mauricio Carvallo², and Eunice Lee $^{3}$}

\begin{abstract}
The purpose of this study was to assess the feasibility of using ethnic beauty salons to reach out to Vietnamese and Korean American women for cervical cancer screening education. Participants $(N=62)$ were conveniently recruited from ethnic beauty salons located in Albuquerque, New Mexico. Two feasibility questionnaires were separately administered to cosmetologists and their customers. Findings support the view that ethnic beauty salons can be used as a gateway to reach out to these populations, and cosmetologists have the potential to operate as community lay health workers to deliver cervical cancer screening education aimed at reducing disparities in cervical cancer and screening to their ethnic customers.
\end{abstract}

\section{Keywords}

cervical cancer, education, ethnic beauty salons, Asian American

\footnotetext{
'University of New Mexico, Albuquerque, USA

2University of Oklahoma, Norman, USA

${ }^{3}$ University of California, Los Angeles, USA

\section{Corresponding Author:}

Jongwon Lee, College of Nursing, University of New Mexico, MSC 09 5350, Albuquerque, NM 87I3I-000I, USA.

Email: jwlee@salud.unm.edu
} 
Vietnamese Americans (VAs) and Korean Americans (KAs) represent the fourth and fifth largest Asian subgroups in the United States, totaling 1.74 million and 1.71 million, respectively (Hoeffel, Rastogi, Kim, \& Shahid, 2012). Both groups are among the fastest growing populations in the country, with their numbers more than doubling in size since 1990 (Hoeffel et al., 2012; U.S. Census Bureau, 2011). Although VAs and KAs still heavily populate California and New York, they have been increasingly relocating to states where small Asian populations have previously resided, such as New Mexico (NM). For instance, Asian Americans comprise a small portion (2\%) of NM's population, but their percentage of growth has been $47 \%$ since 2000 . More importantly, both groups' percentage of growth in NM between 2000 and 2010 (35\%-44\%) was much higher than any other major racial and ethnic group (e.g., non-Hispanic Whites, 16\%), and this trend can also be observed in other states as well (U.S. Census Bureau, 2011). Despite this growth, VAs and KAs have received little attention in research on reproductive cancer control, including cervical cancer, compared with other non-Asian ethnic groups (e.g., African Americans). This fact is alarming because cervical cancer is one of the most commonly diagnosed cancers in this population.

Nationwide studies report that the incidence rates for invasive cervical cancer for VA women (VAW; 18.9/100,000) and KA women (KAW; $11.9 / 100,000$ ) are among the highest in the nation (Wang, Carreon, Gomez, $\&$ Devesa, 2010) and are much higher than those for non-Hispanic White $(7.1 / 100,000)$ and African American $(9.9 / 100,000)$ women. They are also higher than average for other major Asian subgroups (9.1/100,000; Wang et al., 2010). Cervical cancer is the leading cause of death for VAW and the second leading cause of death for KAW (Wang et al., 2010). Despite these high incidence and mortality rates, VAW and KAW consistently report lower screening and early detection rates for cervical cancer than do any other groups. Compared with other Asian subgroups (75\%-89\%) and nonHispanic Whites (88\%; H. Y. Lee, Ju, Vang, \& Lundquist, 2010), KAW rank last (68\%-79\%) and VAW rank third lowest (70\%-81\%) for screening and early detection in the United States (H. Y. Lee, Ju et al., 2010; Pourat, Kagawa-Singer, Breen, \& Sripipatana, 2010). More recent studies that do not include nationwide data report even lower screening rates for both groups (54\%-75\%; Do, 2013; H. Y. Lee, Roh, Vang, \& Jin, 2011; Ma et al., 2012). Overall, these rates are far below the Healthy People 2020 goal for $93 \%$ of women aged 21 to 65 years to have received a cervical cancer screening within the past 3 years (H. Y. Lee et al., 2010; U.S. Department of Health and Human Services, 2011), and they underscore the critical need for additional research on interventions to increase cervical cancer screening among this population. 
Several intervention studies have been conducted in an effort to increase the screening rates for cervical cancer in this population (e.g., Fang, Ma, Tan, \& Chi, 2007; Mock et al., 2007; Moskowitz, Kazinets, Wong, \& Tager, 2007; A. B. Nguyen, Belgrave, \& Sholley, 2011; T. T. Nguyen et al., 2006; Taylor, Jackson, \& Yasui, 2010). Most of these studies have applied multifaceted approaches, including educational materials, counseling, workshops, and navigation assistance, to maximize intervention effects. These studies have frequently utilized indigenous lay health workers (LHWs) to address the psychosocial, cultural, and access barriers to screening among this population. Although a significant number of these studies have revealed positive intervention effects on screening behaviors using indigenous LHWs (e.g., Fang et al., 2007; Mock et al., 2007; T. T. Nguyen et al., 2006), some have reported mixed results or no effects (e.g., Moskowitz et al., 2007; Taylor et al., 2010). One clear conclusion that we can draw from these studies is that identifying appropriate settings that can maximize the access to KAW and VAW and the recruitment of LHWs who are known and trusted by members of these groups are critical for successful intervention outcomes among this population. Based on this conclusion, this study was designed to assess the feasibility of utilizing ethnic beauty salons to reach out to VAW and KAW for cervical cancer screening education as a preliminary step for the development and implementation of an intervention designed to increase the screening rates for cervical cancer in this population.

There are several reasons beauty salons represent an innovative setting where cancer screening interventions can be implemented. First, these locations are usually run by women of the same ethnicity as their clients, often used as a place where ethnic minority women choose to socialize with their cosmetologists and peers, and constitute places where health-related issues are regularly discussed (Linnan, Harrington, Rose, Carlisle, \& Boswell, 2012; Linnan et al., 2007). Second, beauty salons are located throughout the community (Linnan et al., 2012; Linnan et al., 2007) and are easily accessible. Third, most women visit beauty salons regularly (e.g., once every 2 to 7 weeks; Linnan et al., 2012), implying that they are reachable and will be able to be followed for long periods. Fourth, most women tend to use the same cosmetologists at each visit and spend approximately 1.5 to $3 \mathrm{hrs}$ or more with them (Linnan et al., 2012). Accordingly, many women have already built trusted relationships with their cosmetologists, as well as with other women of the same ethnicity who frequent the beauty salon, and are comfortable sharing many aspects of their everyday lives with them. Importantly, many women seek and receive emotional and social support (e.g., advice, empathy) from their cosmetologists in response to their and their families' health crises (Linnan \& Ferguson, 2007; Linnan et al., 2012; Linnan et al., 
2007). Finally, VAW and KAW may consider the topic of cervical cancer to be a particularly sensitive issue, given that their health-related behaviors are strongly bonded to their unique culture. Thus, they should feel more comfortable discussing this topic with someone they are familiar with and with whom they have built a trusted relationship.

In the past, several studies have utilized beauty salons to implement health education programs aimed at promoting healthy eating and physical activity (Johnson, Ralston, \& Jones, 2010; Linnan et al., 2007), adherence to breast cancer screening (Sadler et al., 2011; Wilson et al., 2008), stroke education (Kleindorfer et al., 2008), and chronic disease prevention and organ donation (Madigan, Smith-Wheelock, \& Krein, 2007; Resnicow et al., 2010). These studies have targeted different groups, such as Hispanics and African Americans. The results of these studies suggest that beauty salons constitute an appropriate setting for the dissemination of health promotion messages and can be successfully used to distribute health-related information and provide referrals to appropriate health services. More importantly, these studies support the view that cosmetologists can be utilized as community peer health educators and are likely to influence their customers' health outcomes. To the best of our knowledge, there are currently no salon-based health promotion and intervention programs that focus on Asian American women, and no previous studies have assessed the feasibility of utilizing ethnic beauty salons to deliver cervical cancer screening messages among VAW and KAW.

The framework guiding the conceptualization of this study derives from the diffusion of innovations theory (DIT; Rogers, 2003). The DIT posits that ideas individuals perceive as new (i.e., innovation) are adopted over time. According to this model, there are five types of individuals in the adoption process in terms of their likelihood of adopting ideas or behaviors: (a) innovators (the first individuals to adopt an innovation), (b) early adopters (the second fastest individuals to adopt an innovation), (c) early majority adopters (slower to adopt an innovation than innovators and early adopters), (d) late majority adopters (adopt an innovation after the average member of society), and (e) laggard (the last to adopt an innovation). This model emphasizes that innovators or early adopters may serve as role models for other members of a social system and influence other members' adoption of the innovation. The DIT has been used to conceptualize studies that investigate how cancerrelated behaviors spread through members of society and to identify factors associated with the early adoption of cancer screening (e.g., Hahm, Park, Lee, Park, \& Park, 2011; Tessaro et al., 2013). Based on this perspective, our study explored whether cosmetologists are in a position to deliver cervical cancer-related information to the community by first adopting cancer-related messages and then sharing them with their customers. 
This study was designed to meet the following five specific aims: (a) Determine whether the characteristics of ethnic beauty salons are appropriate in implementing culturally appropriate cancer-related interventions; (b) explore the major conversational topics between VA and KA cosmetologists and their customers of the same ethnic background; (c) assess whether VA and KA cosmetologists are interested in talking about cancer-related material with their customers, and vice versa; (d) explore whether VA and KA cosmetologists are interested in delivering cervical cancer screening-related material to their customers and the type of delivery methods they would prefer to use; and (e) assess VA and KA cosmetologists' comfort levels when discussing cancer-related topics with their customers of the same ethnicity and vice versa, that is, the customers' comfort levels when discussing cancer-related topics with their cosmetologists.

\section{Method}

\section{Design}

A non-experimental, descriptive design was used to address the five aims of this study.

\section{Sample and Setting}

The sample consisted of VA and KA female cosmetologists and their customers of the same ethnic background. Women were included in the study if they were 18 years of age or older; were born either in the United States or in Vietnam or Korea; self-identified as Vietnamese or Korean and their primary language was Vietnamese, Korean, or English; and were able to read, speak, and understand their primary language. A total of 62 participants (18 cosmetologists and 44 customers) were conveniently sampled from ethnic beauty salons that were run by VA and KA cosmetologists located in Albuquerque, NM. These beauty salons provided various services to their customers, including hair and nail services. They varied in size; some were run by a single owner and others had up to five to six employees. The sample included 30 self-identified Vietnamese participants (11 cosmetologists; 19 customers) and 32 self-identified Korean participants ( 7 cosmetologists; 25 customers).

\section{Data Collection Procedures}

Two bilingual research coordinators (one Vietnamese and one Korean) and the principal investigator (PI) identified 15 ethnic beauty salons via social 
networks or the classified sections of newsletters issued by ethnic community organizations. Five of them were run by KA cosmetologists, and the rest were run by VA cosmetologists. Each coordinator (under the guidance of the PI) set up an appointment to meet with the owner of each beauty salon corresponding to her ethnicity. On the day of the appointment, the coordinator and the PI met with the owners of the salons, provided them with a brief description of the purpose of the study, and identified (a) their willingness to allow the investigators to use their beauty salon as a place to recruit potential participants (i.e., employed cosmetologists and customers) and (b) their own interest in participating in this project. Only three beauty salons run by VA cosmetologists refused to participate in the project. After obtaining permission from the owners, the coordinator and the PI approached the cosmetologists and customers from the remaining 12 beauty salons to recruit them for the study.

Data were collected from February 2012 through October 2012. The coordinators and the PI identified the eligibility of cosmetologists and customers and their interest in participating in the study. If they wished to participate, they were explained the study's purpose, the time necessary to complete the questionnaire (15-20 min), the incentive (US\$20 gift card), and their rights as participants. Next, a signed consent form was obtained and the survey was administered to each participant. To standardize and maintain the integrity of the data collection, the research coordinators were trained in the study protocol by the PI.

\section{Measures}

All questionnaires were administered in the participants' primary language (Vietnamese or Korean). A translation and back-translation procedure was applied to achieve a conceptual equivalence between the Vietnamese or Korean and English versions of the questionnaires.

Sample Characteristics Questionnaire. This questionnaire consisted of 16 items, including age, marital status, education, length of residency in the United States, age on entering the United States, smoking status, and so forth.

Feasibility Assessment Questionnaire. Cosmetologists and their customers completed two different questionnaires, developed by the primary investigator. The cosmetologists' questionnaire consisted of 19 items assessing the characteristics of the beauty salons (salon owner status, average number of customers per month, work experiences as cosmetologists, average amount of 
time spent with each customer); the cosmetologists' interest in and comfort with discussing cervical cancer-related information with their customers and delivering cancer-related material to their customers; their interest in learning about cervical cancer-related information from health experts; their preferred ways of learning about and delivering cervical cancer-related materials to their customers; and major topics discussed with customers during each visit. The customers' questionnaire consisted of nine items assessing their interest in and comfort with discussing cervical cancer-related materials with their cosmetologists, their interest in learning about cervical cancer-related information from their cosmetologist, their preferred ways of learning about cervical cancer-related materials, and major topics discussed with cosmetologists per visit.

Questions that assessed participants' interest in and comfort with discussing, learning about, and delivering cervical cancer-related material were presented in a binary format (yes vs. no). Cosmetologists who indicated being interested in discussing cervical cancer-related material with their customers (and vice versa) were asked to rate their degree of interest on a four-point Likert-type scale ranging from 1 (a little) to 4 (very much). Cosmetologists who indicated that they were not comfortable discussing cervical cancer-related material with their customers (and vice versa) were asked to list the reasons why they would not feel comfortable discussing such topics. Open-ended questions were also used to assess the major topics that cosmetologists discussed with their customers (and vice versa). Salon characteristics and utilization were assessed using a six-point Likert-type scale, ranging from 1 (never) to 6 (always), and open-ended questions requiring short answers (e.g., average number of customers that a cosmetologist serves per week).

\section{Analysis}

The quantitative survey data were entered and analyzed using SPSS statistical software (version 20.0). The data were coded and cleaned prior to analysis. Descriptive statistics were used to obtain demographic characteristics, examine variable distributions $(M, S D$, etc.), and determine whether it was appropriate to utilize ethnic beauty salons for future cervical cancer screening education. To determine differences in sample characteristics and outcome (i.e., feasibility assessment) variables, chi-square statistics or independent sample $t$ tests were used. The responses obtained from open-ended questions were analyzed using standard, descriptive, and qualitative content analyses (Miles \& Huberman, 1994). 


\section{Results}

\section{Sample Characteristics}

The average age of the participants was 42.9 years $(S D=11.20$; range $=$ 19-63). Most participants were married (75.8\%) and employed (64.5\%), had more than one child $(76.9 \%)$, and had a high school education or higher $(79.0 \%)$. The mean age when the participants entered the United States was 28.9 years $(S D=14.84)$; their length of residency in the United States was, on average, 16.9 years $(S D=9.50)$. The sample characteristics between VAW and KAW were very similar. However, we did observe differences in education and religion. In our sample, VAW were less educated and predominantly Catholic, whereas KAW were more educated and predominantly Christian. More importantly, VAW and KAW did not significantly differ in terms of feasibility assessment scores (e.g., interest in discussing cervical care-related material), which was our main interest in the study. Table 1 provides information on the participants' characteristics.

\section{Salon Characteristics and Utilization}

The majority of cosmetologists $(61.1 \%)$ indicated that they had had 10 or more years of experience as cosmetologists in the United States, with an average experience of 9.8 years $(S D=4.90)$. In particular, most cosmetologists $(64.7 \%)$ worked at the same beauty salon for 2 years or more, with an average of 4.3 years $(S D=4.74)$. In addition, most customers $(66 \%)$ stated that they visited ethnic beauty salons at least three times or more per year, $M$ $(S D)=4.43$ (3.11). Of these customers, $61 \%$ reported that they always (or very frequently) visited the same beauty salons, $M(S D)=4.75(1.31)$, and $66 \%$ stated that they used the same cosmetologists all the time or very often, $M(S D)=4.91$ (1.36). When asked about the average time spent per service or visit, half of the cosmetologists and $82 \%$ of the customers reported that they spent more than $1 \mathrm{hr}$ during appointments. Table 2 presents data about the salon characteristics and utilization.

\section{Major Topics of Conversation}

The cosmetologists surveyed in this study indicated that they all talked with their customers (and vice versa). The topics discussed included daily life events (e.g., family dynamics and life, finance, jobs), health and illness, and beauty and cosmetics (Table 3). Importantly, $78 \%$ of the cosmetologists reported that they discussed health-related issues with their customers, and 
Table I. Sample Characteristics $(N=62)$.

\begin{tabular}{|c|c|c|}
\hline Characteristics & $n$ & $\%$ \\
\hline \multicolumn{3}{|l|}{ Ethnicity $(n=62)$} \\
\hline Vietnamese & 30 & 48.4 \\
\hline Korean & 32 & 51.6 \\
\hline \multicolumn{3}{|l|}{ Marital status $(n=62)$} \\
\hline Single & 9 & 14.5 \\
\hline Married & 47 & 75.8 \\
\hline Other & 6 & 9.6 \\
\hline \multicolumn{3}{|l|}{ Education $(n=61)$} \\
\hline Middle school or lower & 10 & 16.1 \\
\hline High school & 25 & 40.3 \\
\hline College graduate or higher & 15 & 24.2 \\
\hline Partial college & II & 14.5 \\
\hline \multicolumn{3}{|l|}{ Religion $(n=61)$} \\
\hline Catholic & 18 & 29.0 \\
\hline Christian & 29 & 46.8 \\
\hline Buddhism & II & 17.7 \\
\hline Other & 4 & 6.4 \\
\hline \multicolumn{3}{|l|}{ Number of children $(n=52)$} \\
\hline None & 4 & 7.7 \\
\hline One & 8 & 15.4 \\
\hline Two & 29 & 55.7 \\
\hline Three or more & II & 21.2 \\
\hline \multicolumn{3}{|l|}{ Health insurance $(n=62)$} \\
\hline Yes & 48 & 77.4 \\
\hline No & 14 & 22.6 \\
\hline \multicolumn{3}{|c|}{ Age on entering the United States, (years; $n=62$ ) } \\
\hline$\leq 20$ & 18 & 29.0 \\
\hline $21-30$ & 22 & 35.5 \\
\hline $31-40$ & 17 & 27.4 \\
\hline$\geq 41$ & 5 & 8.1 \\
\hline \multicolumn{3}{|c|}{ Length of residency in the United States, (years; $n=62$ ) } \\
\hline$\leq 10$ & 22 & 35.5 \\
\hline||$-20$ & 16 & 25.8 \\
\hline $21-30$ & 18 & 29.0 \\
\hline$\geq 31$ & 6 & 9.7 \\
\hline \multicolumn{3}{|l|}{ Smoker $(n=62)$} \\
\hline Yes & 3 & 4.8 \\
\hline No & 59 & 95.2 \\
\hline
\end{tabular}


Table 2. Ethnic Beauty Salon Characteristics and Utilization.

\begin{tabular}{|c|c|c|}
\hline Characteristics & $n$ & $\%$ \\
\hline \multicolumn{3}{|l|}{ Cosmetologists $(n=18)$} \\
\hline \multicolumn{3}{|l|}{ Salon owner status } \\
\hline Owner & 6 & 33.3 \\
\hline Employee & 12 & 66.7 \\
\hline \multicolumn{3}{|l|}{ Number of customers/week } \\
\hline$<30$ & 7 & 38.9 \\
\hline$\geq 30$ & II & 61.1 \\
\hline \multicolumn{3}{|l|}{ Time spent with customer/visit } \\
\hline$<\mathrm{hr}$ & 9 & 50.0 \\
\hline$\geq \mathrm{l} \mathrm{hr}$ & 9 & 50.0 \\
\hline \multicolumn{3}{|c|}{ Work experience as cosmetologists } \\
\hline$<10$ years & 7 & 38.9 \\
\hline$\geq 10$ years & 11 & 61.1 \\
\hline \multicolumn{3}{|c|}{ Work experience as cosmetologists at the same beauty salon $(n=17)$} \\
\hline$<2$ years & 6 & 35.3 \\
\hline$\geq 2$ years & 11 & 64.7 \\
\hline \multicolumn{3}{|l|}{ Customers $(n=44)$} \\
\hline \multicolumn{3}{|l|}{ Ethnic beauty salon visits/year } \\
\hline$<3$ times & 15 & 34.1 \\
\hline$\geq 3$ times & 29 & 65.9 \\
\hline \multicolumn{3}{|l|}{ Time spent per visit } \\
\hline$<\mathrm{hr}$ & 8 & 18.2 \\
\hline$\geq \mathrm{l} \mathrm{hr}$ & 36 & 81.8 \\
\hline \multicolumn{3}{|c|}{ Use of same ethnic beauty salons } \\
\hline Always or very frequently & 27 & 61.3 \\
\hline Occasionally & 11 & 25.0 \\
\hline Rarely or very rarely & 6 & 13.7 \\
\hline \multicolumn{3}{|c|}{ Use of same ethnic cosmetologists } \\
\hline Always or very frequently & 29 & 65.9 \\
\hline Occasionally & 9 & 20.5 \\
\hline Rarely or very rarely & 6 & 13.7 \\
\hline
\end{tabular}

$61 \%$ of the customers reported discussing health-related issues with their cosmetologists. When cosmetologists and customers were asked about the specific health-related topics discussed, four major topics emerged from an open-ended question: (a) illnesses, (b) health management and maintenance, (c) health care systems and services, and (d) reproductive health issues. That is, cosmetologists and customers indicated that they often talked with each other about illnesses experienced by their family members or themselves 
Table 3. Major Health Topics Discussed Between Cosmetologists and Customers $(N=62)$.

Health Topics Description

Illness and sickness

Cancer

Diabetes/

hypertension

Pain/aches

Others
Cervical, breast, colon cancer; cancer survivorship and experiences; treatment, such as chemotherapy and surgery; recovery process

Signs and symptoms; medicines and conservative remedies; family history; how to get diagnosed

Back pain; conservative remedies to control pain/aches such as medicated oil, massage, and teas

Arthritis; hepatitis B; depression; thyroid problem; stress; lung problem; tick disorder; medicines good for particular illness; fatigue; surgery experiences; referral and advice related to health problems

Heath management and maintenance

Routine health

Blood pressure; bone density; blood sugar checkup

Vitamins and supplements

Diets

Exercise

Others

Health care systems and services

Systems

Services

Information seeking

Health insurance status and eligibility; accessibility of hospitals/clinics

Vitamin D and calcium to maintain bone health; herbal medicines good for regulating blood pressure; supplements and natural remedies good for body; overthe-counter medicines

Diet problem; healthy eating habits; healthy foods

How to control body weight; types of exercise good for their age

Healthy aging; self-care once getting older; stress management; healthy life; aging without gaining weight

Availability of health care providers; medical malpractice

Where to find quality doctors and services; where to go for medical care, such as stomach and liver problems or colonoscopy

Reproductive health

Sex and sexuality

Menstruation

Perineal hygiene

Menopause
Sexual relationships with partners or husbands

Heaviness or lightness; menstrual cycles

How to keep perineum clean after menses or during pregnancy

Signs and symptoms

(e.g., cancer, diabetes, depression) and how to treat or overcome such health problems (e.g., surgery, recovery process, chemotherapy). They also talked with each other about strategies for maintaining a healthy life (e.g., routine 
health checkups, self-care, vitamins, and exercise). Importantly, some cosmetologists and their customers indicated that they usually discussed problems they previously had experienced when seeking health care services in the United States in terms of accessibility of clinics, insurance, and malpractice. They also exchanged information on where to find quality doctors and services when needed. For example, a cosmetologist stated that she was very familiar with the health care system and services in the United States and shared this information with her customers who had recently immigrated to the United States and who did not know how to access various health services. Last, some of the issues they often discussed were related to reproductive health (e.g., menstrual cycles, perineal hygiene, menopause, and sexuality). One customer, for instance, stated that she talked with a cosmetologist about reproductive issues, such as how to manage menstrual pain.

\section{Cosmetologists' Views: Feasibility Assessment}

The majority of cosmetologists indicated that they were interested in discussing cervical cancer-related topics with customers of their same ethnic background (72.2\%), delivering cervical cancer-related material to them $(100 \%)$, and learning about these topics from health care experts (88.9\%). Of these respondents, more than half expressed a high level of interest in doing so $(61.6 \%, 58.8 \%$, and $56.3 \%$, respectively). Importantly, most cosmetologists stated that they were comfortable discussing these topics with their customers $(72.2 \%)$ and delivering related materials to them (100\%), and expressed a high level of comfort in doing so (69.3\% and 53\%, respectively). When cosmetologists were asked about their preferred methods of learning about the subject, they ranked watching videos the highest (31.3\%), followed by oneon-one talks $(25 \%)$. Similarly, they reported that their most preferred method of delivering such information to their customers was one-on-one talks (47.1\%), followed by distributing pamphlets (29.4\%).

A small number of cosmetologists reported not being interested in or comfortable with talking about cervical cancer-related topics with their ethnic customers $(27.8 \%)$ and did not want to learn about these topics from health care experts (11.1\%). When asked why this was the case, some of them indicated that they had no family history related to cervical cancer or did not engage in sexual activities, assuming that they had no risk of developing cervical cancer. Others stated that illnesses such as cervical cancer were a personal matter or that they were not knowledgeable about cervical cancerrelated topics. Nonetheless, they emphasized that they were willing to talk about cervical cancer-related topics with their customers if they were knowledgeable about such topics and had known their customers for a long time (Table 4). 
Table 4. Cosmetologists' and Customers' Views on the Feasibility of Using Ethnic Beauty Salons for Cervical Cancer Screening Education.

\begin{tabular}{|c|c|c|c|c|}
\hline \multirow[b]{3}{*}{ Items } & \multicolumn{2}{|c|}{$\begin{array}{l}\text { Cosmetologists } \\
\qquad(n=18)\end{array}$} & \multicolumn{2}{|c|}{$\begin{array}{c}\text { Customers } \\
(n=44)\end{array}$} \\
\hline & \multicolumn{4}{|c|}{ Responses } \\
\hline & $n$ & $\%$ & $n$ & $\%$ \\
\hline \multicolumn{5}{|c|}{ Interest in discussing cervical cancer-related topics } \\
\hline No & 5 & 27.8 & II & 25.0 \\
\hline Yes & 13 & 72.2 & 33 & 75.0 \\
\hline \multicolumn{5}{|c|}{ Level of interest in discussing the topics ${ }^{\mathrm{a}}$} \\
\hline A lot or very much & 8 & 61.6 & 18 & 54.5 \\
\hline Somewhat & 3 & 23.1 & 9 & 27.3 \\
\hline A little & 2 & 15.4 & 6 & 18.2 \\
\hline \multicolumn{5}{|c|}{ Comfort discussing cervical cancer-related topics } \\
\hline No & 5 & 27.8 & 5 & $\mathrm{II} .4$ \\
\hline Yes & 13 & 72.2 & 39 & 88.6 \\
\hline \multicolumn{5}{|c|}{ Level of comfort discussing the topics ${ }^{a}$} \\
\hline A lot or very much & 9 & 69.3 & 29 & 74.4 \\
\hline Somewhat & 3 & 23.1 & 8 & 20.5 \\
\hline A little & 1 & 7.7 & 2 & 5.1 \\
\hline \multicolumn{5}{|c|}{ Interest in learning about cervical cancer-related topics } \\
\hline No & 2 & II.I & 5 & $1 \mathrm{I} .4$ \\
\hline Yes & 16 & 88.9 & 39 & 88.6 \\
\hline \multicolumn{5}{|c|}{ Level of interest in learning about the topics ${ }^{a}$} \\
\hline A lot or very much & 9 & 56.3 & 32 & 82.0 \\
\hline Somewhat & 5 & 31.3 & 4 & 10.3 \\
\hline A little & 2 & 12.5 & 3 & 7.7 \\
\hline \multicolumn{5}{|c|}{ Preferred method of learning about the topics ${ }^{\mathrm{a}}$} \\
\hline Watching videos & 5 & 31.3 & 8 & 20.5 \\
\hline One-on-one conversation & 4 & 25.0 & 9 & 23.1 \\
\hline Reading pamphlets & 2 & 12.5 & 7 & 17.9 \\
\hline Visiting websites/online & 2 & 12.5 & 7 & 17.9 \\
\hline Attending workshops & 2 & 12.5 & 4 & 10.3 \\
\hline Group discussions & $\mathrm{I}$ & 6.3 & 4 & 10.3 \\
\hline \multicolumn{5}{|c|}{ Interest in delivering cervical cancer-related material to customers $(n=17)$} \\
\hline No & 0 & 0.0 & & \\
\hline Yes & 17 & 100.0 & & \\
\hline \multicolumn{5}{|c|}{ Level of interest in delivering the materiala } \\
\hline A lot or very much & 10 & 58.8 & & \\
\hline Somewhat & 5 & 29.4 & & \\
\hline A little & 2 & 11.8 & & \\
\hline
\end{tabular}


Table 4. (continued)

\begin{tabular}{|c|c|c|c|c|}
\hline \multirow[b]{3}{*}{ Items } & \multicolumn{2}{|c|}{$\begin{array}{l}\text { Cosmetologists } \\
\qquad(n=18)\end{array}$} & \multicolumn{2}{|c|}{$\begin{array}{l}\text { Customers } \\
(n=44)\end{array}$} \\
\hline & \multicolumn{4}{|c|}{ Responses } \\
\hline & $n$ & $\%$ & $n$ & $\%$ \\
\hline \multicolumn{5}{|c|}{ Preferred method of delivering the material ${ }^{\mathrm{a}}$} \\
\hline One-on-one conversation & 8 & 47.1 & & NA \\
\hline Distributing pamphlets & 5 & 29.4 & & NA \\
\hline Using website/online & 2 & 11.9 & & NA \\
\hline $\begin{array}{l}\text { Others: posters/stickers/ } \\
\text { videos }\end{array}$ & 2 & 11.9 & & NA \\
\hline \multicolumn{5}{|c|}{ Comfort delivering cervical cancer-related material to customers $(n=17)$} \\
\hline No & 0 & 0.0 & & NA \\
\hline Yes & 17 & 100.0 & & NA \\
\hline \multicolumn{5}{|c|}{ Level of comfort delivering the materiala } \\
\hline A lot or very much & 9 & 53.0 & & NA \\
\hline Somewhat & 6 & 35.3 & & NA \\
\hline A little & 2 & 11.8 & & NA \\
\hline
\end{tabular}

Note. NA = not applicable to customers.

a. Questions asked of participants who responded positively to a binary $(\mathrm{Yes} / \mathrm{No})$ question.

\section{Customers' Views: Feasibility Assessment}

Most customers indicated that they were interested in talking about cervical cancer-related topics $(75.0 \%)$ and learning about them $(88.6 \%)$ from their cosmetologists. Of these respective respondents, $54.5 \%$ and $82 \%$ reported a high level of interest in doing so. Most importantly, the majority of customers $(88.6 \%)$ stated that they were comfortable discussing such topics with their cosmetologists and among these, $74.4 \%$ expressed a high level of comfort in doing so. Customers ranked one-on-one talks $(23.1 \%)$ as the most preferred learning method, followed by watching videos (20.5\%; Table 4).

Of the customers who indicated no interest in discussing topics related to cervical cancer with their cosmetologists $(25 \%)$, most expressed concern that cosmetologists were not medical experts and did not know enough about such topics. Thus, they preferred not to talk about these topics with their cosmetologists. Nonetheless, they also said they were willing to talk about such topics if they knew their cosmetologists were educated and knowledgeable about the topics.

Some customers stated that cervical cancer was a sensitive or personal issue and, thus, were reluctant to talk about it with their cosmetologists unless 
they had an in-depth personal relationship with them or felt close enough to them. Others stated that the reasons why they were not interested in talking about cervical cancer-related topics with their cosmetologists were related to their perceptions regarding (a) their young age, (b) regular health checkups within normal limits, and (c) problems with the cervix or uterus associated only with marriage or pregnancy. For instance, some of the young customers tended to perceive that they were healthy and automatically associated their young age with no health-related problems, which in turn, led them to have little interest in talking with, and learning from, their cosmetologists about cervical cancer-related topics. Some customers believed that any reproductive health issues related to the uterus or cervix were exclusively related to those who were married or pregnant, and thus, cervical cancer was not relevant to them. Others stated that their routine checkups were normal, and thus, they had no concerns about their health and no interest in talking about cancer-related topics with their cosmetologists.

\section{Discussion}

The purpose of this pilot study was to assess the feasibility of using ethnic beauty salons to develop and implement a cervical cancer screening education program for VAW and KAW. The study findings support the view that ethnic beauty salons can be utilized as a novel setting to deliver a wide range of cancer-related information and material to this population, and cosmetologists have the potential to operate as LHWs to deliver it to their customers of the same ethnicity. The findings also support the view that customers make use of ethnic beauty salons as socializing venues where they can exchange support and health-related information, and cosmetologists can provide resources to help their customers navigate health care systems and services.

The study findings showed that the majority of cosmetologists had an extensive amount of work experience as cosmetologists in the United States, working at the same beauty salons. This finding suggests that they are used to working in their given environment and have formed a certain level of partnership with their coworkers or owners. The findings also showed that most customers periodically visited the same ethnic beauty salons, used the same cosmetologist for services, and spent a substantial amount of time per visit. This suggests that they have an opportunity to build certain levels of trusted relationships with their cosmetologists for long periods of time and talk about cervical cancer-related topics with each other.

In fact, most cosmetologists and customers already discussed various health-related topics, including cancer, with their customers and cosmetologists, respectively. More importantly, some cosmetologists indicated that 
they have shared health-related information gathered from customers whose expertise was in health-related arenas with other lay customers or had provided health-related information familiar to them to customers in need of such information. Although we were not able to ascertain whether the healthrelated information shared between cosmetologists and customers was accurate (or scientifically sound), these patterns of communication indicate that cosmetologists can play an essential role as navigators for their customers seeking health-related resources or guidance related to health care services and as mediators who can disseminate health-related information among their own customers. Previous studies provide support to the view that beauty salons are places where cosmetologists can openly talk with their customers about many subjects, including health, and are in a position to play the role of helpers who can assist their customers and facilitate referrals to appropriate health agencies (Linnan \& Ferguson, 2007; Linnan et al., 2012; Linnan et al., 2007; Sadler et al., 2011).

The current study showed that both cosmetologists and customers had a great interest in talking about cervical cancer-related issues with their customers and cosmetologists, respectively, and also in learning about cervical cancer from health care experts and their cosmetologists, respectively. Moreover, all cosmetologists expressed an interest in delivering cervical cancer-related material to their customers of the same ethnicity. These findings suggest that there is a great need and interest for cervical cancer-related information among KAW and VAW women, and the development of informative educational material that best meets this need is critical. These findings also suggest that cosmetologists can be utilized as potential lay health educators to deliver cervical cancer-related information to their customers. Although none of the cosmetologists in the current study reported that taking extra time to learn about cervical cancer-related material and provide it to their customers was difficult, previous studies showed that it was challenging due to their busy work schedules (Linnan \& Ferguson, 2007; Linnan et al., 2012). Besides, cosmetologists in the current study indicated that they most preferred to learn about cervical cancer by watching videos and having oneon-one conversations with health care experts. Thus, training programs that take into account their preferences and that are also flexible and do not require physical attendance in a certain place at a specific time must be developed. In particular, given the fact that the majority of cosmetologists are married $(83.3 \%)$ and have children (83.4\%), training programs tailored to their individual needs and that do not take away from their family time are necessary.

Moreover, of those few cosmetologists and customers who reported not being interested in and uncomfortable talking about cervical cancer-related material with their customers and cosmetologists, respectively, most 
expressed concern that cosmetologists were not health experts and not knowledgeable about such topics; thus, they were reluctant to bring these topics into the conversation. This finding indicates the importance of the credibility of information that cosmetologists communicate with their customers and the level of knowledge and skills that customers expect from their cosmetologists. Strategies maximizing the authenticity of information exchanged between cosmetologists and customers and enhancing cosmetologists' confidence in their roles as lay health educators must be taken into account when developing training programs. For example, issuing a certificate to cosmetologists who completed certain training programs and tests will provide assurance not only to cosmetologists but also to customers that the cervical cancer-related information delivered by cosmetologists is credible. The display of pamphlets that contain cervical cancer-related information and that are in accordance with the information delivered by cosmetologists in ethnic beauty salons will also enhance customers' assurance that the information that they receive from cosmetologists is current and accurate.

Finally, of those cosmetologists and customers who reported no interest in talking about cervical cancer-related material with each other or learning about it from health care experts and cosmetologists, some believed, incorrectly, that only those who had a family history of cancer, were sexually active, or had been married or pregnant could develop cervical cancer. These erroneous perceptions led them to believe that women who are young, single, not sexually active, and have no family history of cancer are not at risk of developing cervical cancer and do not need to receive screening. To dispel such misbeliefs, it is extremely important to develop and implement culturally appropriate interventions that can enhance cancer-related knowledge and awareness in this population. Particularly, it is important to develop interventions that apply multifaceted approaches (e.g., personalized letters, audiovisual talks, mobile screening services) and combine additional support (e.g., transportation assistance: Glick, Clarke, Blanchard, \& Whitaker, 2012; Lu et al., 2012).

The current study had several limitations. First, the sample consisted solely of VA and KA cosmetologists and customers at ethnic beauty salons located in the city of Albuquerque, NM. Thus, the findings cannot be generalized to VAW and KAW living in other regions in the country, other Asian American subgroups (e.g., Chinese), or Vietnamese and Korean cosmetologists and customers working in and using beauty salons that do not solely serve VAW and KAW. Second, this was a pilot study aimed at providing preliminary data for the development of community-based cancer screening educational programs for VAW and KAW. Thus, the sample size was relatively small. Moreover, the study participants were conveniently recruited; 
thus, it was not representative of the entire population, limiting the external validity of the findings. Third, selection bias may also be considered a limitation, given that most participants were married (75.8\%), older (i.e., $71 \% \geq 40$ years), and had children (76.9\%). A recent qualitative study conducted by the authors showed that women's marital status, age, and family responsibilities were one of the major factors influencing their perceived susceptibility to and risk of cervical cancer, intention to get screened, and actual screening behaviors (J. Lee, Carvallo, \& Lee, 2013). For instance, because of their age, older women tend to perceive an increased risk of illness, think about getting checkups and screening, and are more familiar with women's health issues, such as cervical cancer, compared with younger women. Eventually, this might result in greater levels of interest in learning about and discussing cervical cancer-related topics among participants in the current study. From this viewpoint, the study findings should be cautiously interpreted, and future research should assess populations who are younger and single.

The current study derived from a critical need for additional research on cervical cancer screening education programs that could maximize access to VAW and KAW, in particular, those who might not be reached through traditional outreach programs. This study constitutes the first attempt to assess (a) whether ethnic beauty salons could be utilized as a novel setting to deliver a wide range of cervical cancer-related material to Asian American women, especially VAW and KAW, and (b) whether cosmetologists had the potential to operate as LHWs to deliver cervical cancer screening education to customers of the same ethnicity. The results of the study support the feasibility of using ethnic beauty salons and cosmetologists to deliver such programs. These programs are urgently needed to reduce disparities in cervical cancer in these populations.

\section{Declaration of Conflicting Interests}

The author(s) declared no potential conflicts of interest with respect to the research, authorship, and/or publication of this article.

\section{Funding}

The author(s) disclosed receipt of the following financial support for the research, authorship, and/or publication of this article: Support for this research was provided by the Oncology Nursing Society Foundation and University of New Mexico Clinical and Translational Science Center (DHHS/NIH/NCRR Grant UL1RR031977).

\section{References}

Do, M. (2013). Predictors of cervical cancer screening among Vietnamese American women. Journal of Immigrant and Minority Health. Retrieved from http://link. springer.com/article/10.1007/s10903-013-9925-2/fulltext.html 
Fang, C. Y., Ma, G. X., Tan, Y., \& Chi, N. (2007). A multifaceted intervention to increase cervical cancer screening among underserved Korean women. Cancer Epidemiology, Biomarkers \& Prevention, 16, 1298-1302.

Glick, S. B., Clarke, A. R., Blanchard, A., \& Whitaker, A. K. (2012). Cervical cancer screening, diagnosis and treatment interventions for racial and ethnic minorities: A systematic review. Journal of General Internal Medicine, 27, 1016-1032. doi:10.1007/s11606-012-2052-2

Hahm, M.-I., Park, E.-C., Lee, H.-Y., Park, J.-Y., \& Park, S. (2011). Inequalities in adoption of cancer screening from a diffusion of innovation perspective: Identification of late adopters. Cancer Epidemiology, 35, 90-96. doi:10.1016/j. canep.2010.08.009

Hoeffel, E. M., Rastogi, S., Kim, M. O., \& Shahid, H. (2012). The Asian population: 2010. 2010 Census briefs. Retrieved from http://www.census.gov/prod/cen2010/ briefs/c2010br-11.pdf

Johnson, L. T., Ralston, P. A., \& Jones, E. (2010). Beauty salon health intervention increases fruit and vegetable consumption in African American women. Journal of the American Dietetic Association, 110, 941-945. doi:10.1016/j. jada.2010.03.012

Kleindorfer, D., Miller, R., Sailor-Smith, S., Moomaw, C. J., Khoury, J., \& Frankel, M. (2008). The challenges of community-based research: The beauty shop stroke education. Stroke, 39, 2331-2335.

Lee, H. Y., Ju, E., Vang, P. D., \& Lundquist, M. (2010). Breast and cervical cancer screening among Asian American women and Latinas: Does race/ethnicity matter? Journal of Women's Health, 19, 1877-1884. doi:10.1089/jwh.2009.1783

Lee, H. Y., Roh, S., Vang, S., \& Jin, S. W. (2011). The contribution of culture to Korean American women's cervical cancer screening behavior: The critical role of prevention orientation. Ethnicity \& Disease, 21, 399-405.

Lee, J., Carvallo, M., \& Lee, E. (2013, April). Psychosocial-ecological perspectives on Asian women's cervical cancer screening behaviors. Poster presented the 46th Annual Western Institute of Nursing Conference, Anaheim, CA.

Linnan, L., \& Ferguson, Y. (2007). Beauty salons: A promising health promotion setting for reaching and promoting health among African American women. Health Education \& Behavior, 34, 517-530.

Linnan, L., Harrington, C. B., Rose, J. M., Carlisle, V., \& Boswell, M. (2012). The North Carolina BEAUTY and Health Project: Preventing cancer in African American beauty salons. In R. Elk \& H. Landrine (Eds.), Cancer disparities: Causes and evidence-based solutions (pp. 211-236). New York, NY: Springer.

Linnan, L., Rose, J., Carlisle, V., Evenson, K., Hooten, E. G., Mangum, A., . . . Biddle, A. (2007). The North Carolina BEAUTY and Health Project: Overview and baseline results. The Community Psychologist, 40, 61-66.

Lu, M., Moritz, S., Lorenzetti, D., Sykes, L., Straus, S., \& Quan, H. (2012). A systematic review of interventions to increase breast and cervical cancer screening uptake among Asian women. BMC Public Health, 12, 1-16. doi:10.1186/14712458-12-413

Ma, G. X., Fang, C. Y., Feng, Z., Tan, Y., Gao, W., Ge, S., \& Nguyen, C. (2012). Correlates of cervical cancer screening among Vietnamese American women. 
Infectious Disease in Obstetrics and Gynecology, 2012, Article 617234. doi:10.1155/2012/617234

Madigan, M. E., Smith-Wheelock, L., \& Krein, S. L. (2007). Healthy hair starts with a healthy body: Hair stylists as lay health advisors to prevent chronic kidney disease. Preventing Chronic Disease, 4, Article A64. Retrieved from http://www. cdc.gov/pcd/issues/2007/jul/06_0078.htm

Miles, M. B., \& Huberman, A. M. (1994). Qualitative data analysis: An expanded sourcebook (2nd ed.). Thousand Oaks, CA: SAGE.

Mock, J., McPhee, S. J., Nguyen, T., Wong, C., Doan, H., Lai, K. Q., . . Bui-Tong, N. (2007). Effective lay health worker outreach and media-based education for promoting cervical cancer screening among Vietnamese American women. American Journal of Public Health, 97, 1693-1700.

Moskowitz, J. M., Kazinets, G., Wong, J. M., \& Tager, I. (2007). "Health is strength": A community health education program to improve breast and cervical cancer screening among Korean American women in Alameda County, California. Cancer Detection and Prevention, 31, 173-183.

Nguyen, A. B., Belgrave, F. Z., \& Sholley, B. K. (2011). Development of a breast and cervical cancer screening intervention for Vietnamese American women: A community-based participatory approach. Health Promotion Practice, 12, 876-886.

Nguyen, T. T., McPhee, S. T., Bui-Tong, N., Luong, T. N., Ha-Iaconis, T., Nguyen, T., . . Lam, H. (2006). Community-based participatory research increases cervical cancer screening among Vietnamese Americans. Journal of Health Care for the Poor and Underserved, 17(2 Suppl.), 31-54.

Pourat, N., Kagawa-Singer, M., Breen, N., \& Sripipatana, A. (2010). Access versus acculturation: Identifying modifiable factors to promote cancer screening among Asian American women. Medical Care, 48, 1088-1096. doi:10.1097/ MLR.0b013e3181f53542

Resnicow, K., Andrews, A. M., Beach, D. K., Kuhn, L., Krein, S. L., Chapman, R., \& Magee, J. C. (2010). Randomized trial using hair stylists as lay health advisors to increase donation in African Americans. Ethnicity \& Disease, 20, 276-281.

Rogers, E. M. (2003). Diffusion of innovations (5th ed.). New York, NY: Free Press.

Sadler, G. R., Ko, C. M., Wu, P., Alisangco, J., Castañeda, S. F., \& Kelly, C. (2011). A cluster randomized controlled trial to increase breast cancer screening among African American women: The Black cosmetologists promoting health program. Journal of the National Medical Association, 103, 735-745.

Taylor, V. M., Jackson, J. C., \& Yasui, Y. (2010). Evaluation of a cervical cancer control intervention using lay health workers for Vietnamese American women. American Journal of Public Health, 100, 1924-1929.

Tessaro, I., Campbell, M. K., Golden, S., Gellin, M., McCabe, M., Syrjala, K., . . . Rosenstein, D. L. (2013). Process of diffusing cancer survivorship care into oncology practice. Translational Behavioral Medicine, 3, 142-148. doi:10.1007/ s13142-012-0145-4

U.S. Census Bureau. (2011, April). Profile America: Facts for features: Asian/Pacific American heritage month: May 2011. Retrieved from http://www.census.gov/ newsroom/releases/archives/facts_for_features_special_editions/cb11-ff06.html 
U.S. Department of Health and Human Services. (2011, September 1). Healthy People 2020 cancer objectives: Cancer. Retrieved from http://www.healthypeople.gov/2020/topicsobjectives2020/objectiveslist.aspx?topicid $=5$

Wang, S., Carreon, D., Gomez, S. L., \& Devesa, S. S. (2010). Cervical cancer incidence among 6 Asian ethnic groups in the United States, 1996 through 2004. Cancer, 116, 949-956. doi:10.1002/cncr.24843

Wilson, T. E., Fraser-White, M., Feldman, J., Homel, P., Wright, S., King, G., . . . Browne, R. (2008). Hair salon stylists as breast cancer prevention lay health advisors for African American and Afro-Caribbean women. Journal of Health Care for the Poor and Underserved, 19, 216-226. doi:10.1353/hpu.2008.0017 